\title{
Discurso público y manipulación: el caso de Julio César
}

\section{Public discourse and manipulation: the case of Julius Caesar}

\author{
JESÚS ALCOLEA BANEGAS ${ }^{1}$ \\ Universitat de València
}

Recibido: 25/06/2013 Aceptado: 02/09/2013

\section{RESUMEN}

Analizamos la manipulación en el discurso público, siguiendo el drama shakespeareano Julio César y la versión fílmica de J.L. Mankiewicz. Al centrarse este discurso en la acción, son menos útiles los argumentos coherentes y bien elaborados que las apelaciones emotivas y las imágenes impactantes. Se oculta la verdad con una retórica brillante, pero perniciosa. Solo la participación activa ante la recepción de un discurso manipulador, sin renunciar a la argumentación retórica, puede ponernos en guardia de forma crítica, racional y razonable.

\section{PALABRAS CLAVE \\ DISCURSO PÚBLICO, MANIPULACIÓN, RETÓRICA, ACTOS DE HABLA, ARGUMENTACIÓN}

\begin{abstract}
We analyze manipulation in public discourse through the Shakespearean drama Julius Caesar, and J.L. Mankiewicz's film version. As the focus of the discourse is placed on the action, well designed coherent arguments in the discourse become less useful than emotional appeals and

1 El texto se basa en investigación realizada en el marco de los proyectos FFI2008-00085 y FFI2011-23125 del Ministerio de Ciencia e Innovación. Agradecemos a nuestros colegas sus lúcidos comentarios a borradores previos. Este trabajo se inició con el curso La argumentación y las prácticas de argumentar en la gestión del discurso público, celebrado en Santander en julio de 2010.
\end{abstract}

(C) Contrastes. Revista Internacional de Filosofia, vol. XIX-N²2 (2014), pp. 379-398. ISSN: 1136-4076

Departamento de Filosofía, Universidad de Málaga, Facultad de Filosofía y Letras Campus de Teatinos, E-29071 Málaga (España) 
striking images. It hides the truth with brilliant but pernicious rhetoric. When confronted with a manipulating discourse, only active participation, without giving up rhetorical argumentation, can keep up our guard against manipulation in a critical, rational and reasonable way.

KEYWORDS

PUBLIC DISCOURSE, MANIPULATION, RHETORIC, SPEECH ACTS, ARGUMENTATION

\section{INTRODUCCIÓN}

EL DISCURSO PÚBLICO SUELE ESTAR DOMINADO por las declaraciones grandilocuentes sobre la capacidad $\mathrm{u}$ honestidad de los oradores, por las referencias abstractas a determinadas creencias, por las disquisiciones sobre la grandeza del pasado, por los mensajes intimidatorios (más o menos velados) sobre la perversidad del adversario y por los peligros apocalípticos que amenazan a la civilización y sus valores. Es un discurso imaginativo y creativo que defiende determinados intereses sirviéndose de la distorsión o la manipulación más que de la verdad y recurriendo a mecanismos que enervan las emociones del auditorio más que a resortes lógicos, pues el objetivo es impulsar la acción con un determinado fin. Sin embargo, frente a cierta tradición que atribuye pasividad al auditorio, el modo de proceder no es unidireccional, pues el discurso del orador está influido por el mundo mental de su auditorio y sus expectativas. Ahora bien, hay que decirlo de manera que se pueda rentabilizar el esfuerzo de elaborar un discurso que, al final, siempre estará al servicio de unos intereses más o menos velados. El orador se centrará en lo que tiene éxito, en lo que el auditorio le pide, en lo que (él ve que) agrada a su auditorio y en lo que a su vez le seduce.

Quien argumenta trata de presentar buenas razones a favor de la causa (creencia o acción) que desea defender y, si puede, influir en las decisiones que espera que su interlocutor adopte. Pero, si no tiene intención de manipular, no se preocupa de ocultar sus estrategias para que ese interlocutor sea consciente de su modo de proceder y objetivos. La manipulación fructifica cuando el manipulado no se percata de que está siendo manipulado. Para conseguir su objetivo, el manipulador se interesará por las preocupaciones de sus interlocutores, para pasar a elaborar su estrategia, tras sedimentarla en ese conocimiento. Comenzará anulando la capacidad de su víctima para pensar críticamente, actuando inmediatamente sobre su estado afectivo y sus sentimientos, y tergiversando cualquier atisbo de razonamiento de que pueda ser capaz. ${ }^{2}$

2 Según Nettel y Roque 2012, p. 58, la manipulación presenta tres aspectos: el disimulo de la intención de manipular, la presión (o coacción) ejercida sobre la persona a manipular, y la obstrucción de la libertad de la persona para elegir. 
Nuestro objetivo será analizar el papel de la manipulación en el discurso público, siguiendo el ejemplo del Julio César en la versión fílmica de J.L. Mankiewicz (1953), sin olvidar la gran belleza literaria y la genialidad poética del texto de W. Shakespeare $(2001,2002)$, en el que se inspira, y que el realizador de Pensilvania asimila rayando la perfección. Los diálogos no pesan sobre el espectador, ya que están integrados en la acción misma. En la obra, la lucha por el poder tiene unos motivos poco elevados (la ambición) y otros completamente desinteresados (el patriotismo), con los conflictos que se producen entre el afecto y el deber, lo que confiere una enorme grandeza moral a los protagonistas. Como el dramaturgo, Mankiewicz trata esos conflictos entre afecto y deber con una buena dosis de ambigüedad, dejando que cada personaje aclare y defienda sus posiciones, actitud que culmina en los discursos de Bruto y Antonio, ante un pueblo voluble y manejado con razones emotivas. Todo ello suscita múltiples reflexiones y analogías sobre la legitimidad del poder, el uso correcto de las instituciones, el liderazgo carismático, la tiranía y la legitimidad o no del tiranicidio. Resulta llamativo el contraste entre las intrigas de los políticos y la necesidad de conseguir el beneplácito de la plebe, subrayando la teatralidad de la política y de los hombres públicos. Bruto y Antonio se dirigen a la plebe convenciéndola de cuál es el bien del pueblo de Roma. Bruto parece un hombre honesto que expone su causa abiertamente, invocando el honor y la dignidad, mientras que Antonio es un sutil manipulador, un zorro frente a un león. Siendo además un maestro de la ironía, ésta actúa a la vez sobre él. Al principio es un indolente seguidor de César, pero va mostrando sus verdaderas intenciones, engañando con un llamativo juego de dolor y nobleza, sublevando a la plebe y demostrando que su oración fúnebre sigue siendo una obra maestra de retórica manipuladora.

El film refleja de forma impresionante los espacios públicos de la antigua Roma, con una hermosa fotografía que recuerda los montajes escénicos del nazismo (Wyke 2004), y, aunque está lleno de matices, es deudor de las representaciones teatrales. Mankiewicz dividió la historia en dos partes: la trama que lleva a la muerte de César y sus consecuencias. Y estructuró el relato en torno a los personajes y a los sucesos que les afectan: la entrada triunfal de César y su dudoso éxito, la tormenta, los ruegos de Porcia y los de Calpurnia a sus respectivos esposos, Bruto y César, la muerte de éste, y la batalla de Filipos. Para nuestros propósitos, destacan el diálogo inicial entre Casio y Bruto, el soliloquio de éste y su discurso y el de Antonio ante la plebe.

En un mundo donde prevalecen los intereses públicos sobre las actuaciones privadas, donde el engaño y el disimulo son las formas habituales de relación, no cabe un lenguaje sincero que refleje los sucesos cotidianos, ni un lenguaje poético que exprese los aspectos más personales. El film retrata precisamente ese mundo de públicos intereses, a los que se subordina todo lo 
privado. Las casas de Bruto y César están abiertas al exterior, mostrando la continuidad entre lo público y lo privado, pero subrayando la oscuridad de la dimensión privada de los personajes y la poca reflexión conferida a los asuntos públicos. Las conversaciones de Porcia y Calpurnia con sus esposos, volcados hacia lo público, giran justamente sobre esta ausencia de privacidad y sobre la escasa confidencialidad de sus preocupaciones políticas. El soliloquio de Bruto, que podría ser una excepción, transcurre en un espacio poco privado (el patio, al cual se accede desde el exterior) y en términos públicos: los motivos para la muerte de César. En general, los grandes acontecimientos transcurren en sitios públicos, donde la palabra puede tener mayor eco y donde se han de producir los principales movimientos en sentido físico y figurado, pues es donde la mente y el corazón de los personajes, especialmente de la plebe, sufrirán los mayores cambios (cf. Mangan 1992). Así, la apelación clave de Antonio al testamento de César, un asunto privado, se revela públicamente al beneficiario: la multitud. Y para rizar el rizo de lo público, algo privado -los jardines de César- deviene público, para disfrute de los ciudadanos. En el terreno de lo público, que es donde se manifiestan y revelan las cosas, se da la paradoja de que es donde se oculta la verdad a través de la retórica brillante, pero perniciosa, de la manipulación.

\section{EL USO DE LA RETÓRICA}

En el Julio César, la Roma de los hábiles oradores permite a Shakespeare elaborar un drama que es una crítica de la peor retórica y del uso perverso del lenguaje, pues la pericia retórica de aquellos oradores puede enmascarar la verdad (política y moral), y los problemas que el lenguaje acarrea generan, a su vez, problemas epistémicos. No en vano el dramaturgo pone en boca del personaje que encarna a Cicerón que «los hombres interpretan las cosas a su modo y se apartan de su recto sentido» (1.3.34-35). ${ }^{3}$ En el texto y en su versión fílmica se evidencia la necesidad de recurrir a la retórica a todos los niveles. En general, las estrategias son típicas del enmascaramiento y del engaño. Los personajes se observan mutuamente, prestando atención a las acciones y a los gestos de los demás para averiguar sus verdaderas intenciones. Por ello, los aspectos visuales contribuyen al aumento de tensión, sobre todo dependiendo de la interpretación que se les vaya dando. Así, la intranquilidad de Porcia o la relevancia de los avisos que César recibe están relacionados con la visión, pero también con lo que no se ve, quedando, por ello, sujetos a interpretación (el ciego adivino, el sueño de su esposa, los resultados negativos de los sacrificios y los extraños fenómenos atmosféricos). Cabe destacar la visión práctica de César al describir de forma penetrante a Casio, capacidad que queda cuestio-

3 Las referencias numéricas proceden de Shakespeare 2001 y 2002. 
nada cuando un hábil adulador le regala los oídos con aquello que desea oír. En conversación con Bruto y Casio, ésta será al menos la opinión de Decio, quien, como contraste, subraya que a César no le agradan los aduladores (2.1.216-221).

Bruto y Antonio merecen un comentario especial. El primero, poco práctico, parece estar alejado de toda realidad. Su diálogo con Casio se reduce a intercambios argumentativos abstractos en respuesta a propuestas concretas. Esta tendencia se repite en su soliloquio, que comienza por la conclusión que desea establecer - «El remedio está en su muerte» (2.1.10)-, lanzándose a buscar argumentos justificatorios, y que no disipará las dudas que invaden su angustiado espíritu. El caso de Antonio es diferente y sorprendente. Después de presentarse como persona despreocupada y confiada en el buen hacer de César, se revelará como un hábil y práctico manipulador, deseoso de satisfacer sus intereses. Él mismo nos ofrece su propio retrato manipulado. Recurriendo a una figura retórica, el clenasmo, de acuerdo con la cual uno mismo se deprecia para garantizar una mejor apreciación de él y de lo que dice, Antonio finge ante la plebe no ser un experto en oratoria: «No soy orador como Bruto, sino, como todos sabéis, un hombre claro y franco [...] Yo hablo sin floreos; os digo lo que sabéis...» (3.2.221-222, 227-228). Es decir, pretende carecer de ingenio o inteligencia, de prestancia o fluidez, de soltura y de ese peso que procede del carácter (auctoritas), de gestos y movimientos corporales adecuados y, finalmente, de la facilidad en la elocución, «el don de palabra para excitar las pasiones» (3.2.226-227).

Antonio no entiende la retórica como Bruto. Sus estilos son diferentes, como las palabras y frases que usan, los recursos simbólicos, la duración de cada discurso y la interacción con la plebe, las razones que presentan y la viveza de las descripciones y manifestaciones, siendo abstractas e intangibles para Bruto y concretas y sensibles para Antonio. Tras la muerte de César, aquél se siente culpable y llega incluso a insinuar un posible castigo. Como la cámara de Mankiewicz muestra, al enfocar su rostro en dos momentos clave, Antonio se siente como el gran manipulador que es. Bruto construye su discurso sobre su figura como orador, su honradez y moralidad, justificando sus posiciones éticas y políticas y la disposición para el sacrificio personal. Antonio, en cambio, construye su discurso sobre la supuesta honradez de los asesinos, sobre algunas acciones de César y sobre su cuerpo yacente, pero también sobre su supuesta ignorancia en materia de oratoria, con la cual logra cierto efectismo. Antonio sabe que para inducir a la acción a las multitudes no hace falta argumentar de manera correcta, sino transmitir pasión o apelar a valores morales. Tras aclarar que la retórica se ocupa de estudiar los medios de que disponemos para persuadir, Aristóteles lo observó afirmando que en «las pruebas por persuasión, las que pueden obtenerse mediante el discurso son de tres especies: unas residen en el talante del que habla [êthos], otras en predisponer al oyente 
de alguna manera [pathos] y, las últimas, en el discurso mismo [logos], merced a lo que éste demuestra o parece demostrar» (Retórica, 1356a1-4). Ahora bien, añade, el orador ha de atender «a los efectos del discurso, no sólo a que sea demostrativo y digno de crédito, sino también a cómo 'ha de presentarse' uno mismo y a cómo inclinará a su favor al que juzga. Porque es muy importante para la persuasión [...] el modo como se presente el orador y el que se pueda suponer que él está en una cierta actitud respecto de los 'oyentes', así como, en lo que se refiere a éstos, el que se logre que también ellos estén en una determinada actitud 'ante el orador'», para conducirlos al estado emocional adecuado (1377b22-29).

La estructura pathos, êthos, logos del discurso de Antonio contrasta con la del discurso de Bruto, que es más ordenada, êthos, logos, pathos. Desde antes de empezar a hablar, la nobleza (êthos) de Bruto impresiona a su público. Así un ciudadano declara: «El muy noble Bruto está en la tribuna. ¡Silencio!» (3.2.10). Después, sus razones (logos) («Oíd mis razones y guardad silencio para poder oír» (3.2.14-15)) acaban en la petición de disculpas por si han ofendido a alguien. Pero concluye su discurso tratando de afectar las emociones (pathos) de los ciudadanos afirmando «así como maté a mi mejor amigo por el bien de Roma, volveré el puñal contra mí mismo cuando mi patria estime necesaria mi muerte» (3.2.42-44), a lo que todos responden con vítores. Al final de la primera parte del discurso de Antonio, que un ciudadano afirme «Yo creo que tiene razón en lo que dice» (3.2.112) (logos) prueba que su discurso no se reduce al puro pathos. Que la declaración realizada a continuación por otro ciudadano, «iEn Roma no hay hombre más noble que Antonio!» (3.2.121), muestra que el carácter de Antonio les ha impresionado (êthos), y por la exclamación del anterior «iEl pobre! Tiene los ojos rojos como el fuego de tanto llorar» (3.2.120) sabemos que les ha conmovido (pathos). Pero esta conmoción irá en aumento a medida que Antonio vaya echando lecha al fuego. Al final, sin embargo, no estamos en mejores condiciones para juzgar la verdad de las declaraciones de Bruto que las de Antonio. Nos hemos quedado a merced de la peor retórica y sin la fuerza de la razón. Ello explica la ambigüedad reinante en toda la obra: si un punto de vista se formula de forma persuasiva, se acepta de forma entusiasta como si fuera una verdad absoluta.

\section{LA MANIPULACIÓN COMO FENÓMENO DISCURSIVO Y COMO ACTO DE HABLA: CONTRA LAS MÁXIMAS CONVERSACIONALES}

Aunque las esferas política y publicitaria son terrenos privilegiados de la manipulación, la verdad es que todos podemos caer en la tentación de manipular en cualquier ámbito. La manipulación encierra una actuación moral perversa, que puede no compensar la eficacia perseguida, porque puede afectar a la calidad de las relaciones humanas y a la propia reputación e imagen: un 
manipulador puede resultar un cazador cazado. El manipulador ha de ser paciente en la espera de su presa (información, conocimiento), astuto como un zorro (la mejor estrategia argumentativa -lógica y retórica-) y rápido como un felino (el tiempo puede jugar en su contra).

La acepción del verbo «manipular» que nos interesa no es la técnica (sobre objetos) (cf. Ilatov 1993), sino la intervención hábil, artera, en la política, en el mercado, en la información, etc., distorsionando la verdad, y al servicio de intereses ocultos. Es un punto de vista simbólico o comunicativo, sobre humanos como objetos. Esta acepción suele manifestarse de forma discursiva interactiva y el manipulador ejerce su control sobre otras personas. Se diferencia de la persuasión en que con ésta tratamos de conseguir que alguien se ponga de acuerdo con nosotros por medio de argumentos. Aunque también puede recurrir a argumentos, el manipulador trata de conseguir de manera deshonesta que una persona haga algo, aprovechándose de ella. Podemos hacer seis observaciones a esta idea de manipulación (cf. van Dijk 2009, p. 352):

$\left(1^{\mathrm{a}}\right)$ La manipulación conlleva (abuso de) poder y dominación.

$\left(2^{\mathrm{a}}\right)$ La manipulación es una forma ilegítima de influir con el discurso.

$\left(3^{\mathrm{a}}\right)$ La influencia ilegítima se puede hacer por cualquier medio comunicativo: la manipulación es multimodal. ${ }^{4}$

(4 $\left.{ }^{\mathrm{a}}\right)$ El manipulador consigue que el manipulado crea y haga cosas beneficiosas para el manipulador y, posiblemente, perjudiciales para el manipulado.

(5) Al compararla con la persuasión, observamos que (a) en ésta los interlocutores son libres de creer o actuar como les plazca (papel activo), si aceptan o no los argumentos del persuasor. (b) En la manipulación, a los interlocutores se les asigna un papel más pasivo: son víctimas y no deben ser conscientes de la estrategia del manipulador. (c) La persuasión es dialógica y se ve, mientras que la manipulación no es dialógica y no se ve: se sufre. (d) La persuasión es confesable y hay una relación intrínseca, pero manifiesta, entre las razones del persuasor y sus intenciones. (e) El manipulador oculta sus intenciones reales. (f) El manipulado no puede comprender las intenciones o las consecuencias reales de las creencias o acciones defendidas por el manipulador: la ignorancia epistémica le torna vulnerable y no puede resistirse a la manipulación.

$\left(6^{\mathrm{a}}\right)$ Hay quien piensa que toda comunicación es manipuladora por sí misma, porque tiene como objetivo cambiar y, por tanto, manipular la conducta de otros humanos. En cierto modo, para que la comunicación no sea manipuladora ha de ser ineficaz. Puesto que la retórica busca la eficacia del

4 Multimodal porque el manipulador no sólo puede servirse de cualquier medio a su alcance, sino porque éste puede ser lógico, emocional, visceral, etc. (cf. Gilbert 1997). 
discurso, toda retórica sería manipuladora, lo cual nos abocaría a la cultura de la sospecha.

Ahora bien, la manipulación es un fenómeno inevitablemente social, fruto de la interacción en una determinada situación. Es un fenómeno cognitivo, porque afecta las mentes, y es un fenómeno discursivo, porque interviene un lenguaje verbal, escrito o visual. En la interacción (argumentativa), algunas propiedades del discurso influyen en el proceso. Por ejemplo, el estilo puede apuntar a algunas propiedades del contexto y subrayar significados apropiados. Los recursos retóricos pueden resaltar esos significados en función del objetivo, y la interpretación del significado de algunas afirmaciones o imágenes puede determinar el proceso de forma vital. Esto es, las manipulaciones se manifiestan en un conjunto de enunciados relacionados y con más de un significado, que deben ser interpretados por la persona a manipular, que están formulados con una determinada intención, que tratan de conseguir que esa persona partícipe de una determinada opinión o que actúe de una determinada manera, según el plan del manipulador. Como fenómeno discursivo, cabe subrayar la intencionalidad y el instrumentalismo de las manipulaciones que usan a las personas como objetos, de modo que los manipuladores exhiben (ocultamente) una destreza (manipuladora) dirigida por fines. Por ello, la manipulación es un acto de habla.

¿Y qué es un acto de habla? ${ }^{5}$ Es una acción humana con la que un agente intenta alcanzar un determinado fin con el lenguaje. Éste es una parte constitutiva, como lo son las intenciones del hablante y las reacciones del oyente. En dicha acción, encontramos tres factores. El acto locutivo, que corresponde con la expresión de algo (aquello que se dice). El acto ilocutivo, que corresponde a lo que pretendemos hacer al decir algo, con lo que es distinto del decir algo (la intención concreta del acto de habla). Y el acto perlocutivo, que corresponde a lo que se consigue con el acto de habla (el efecto que el enunciado produce en el receptor en una determinada circunstancia), y que puede coincidir con la intención del hablante. Al unir la pretensión del hablante con lo que se consigue, es decir, la ilocución y la perlocución, estamos en el seno de la retórica como arte del discurso que busca la eficacia en la acción.

Los actos de habla se pueden dividir, además, en dos tipos. Los actos directos son aquellos enunciados en los que el aspecto locutivo e ilocutivo coinciden, expresando directamente la intención. Y los actos indirectos son aquellos en los que el aspecto locutivo e ilocutivo no coinciden, por lo que la

5 Para más detalles sobre los actos del habla, puede verse la entrada 'Actos de habla' en Vega y Olmos (Eds.) 2011. Para este trabajo también son útiles las entradas 'Retórica', 'Argumento visual', 'Auditorio', 'Principio de cooperación', 'Máximas de la conversación', 'Elocución', 'Falacia', 'Ironía', etc. 
intención es distinta de lo directamente expresado. Por tanto, la manipulación sería un acto de habla indirecto. Además, desde el punto de vista de la teoría de los actos de habla, las expresiones manipuladoras poseen estos rasgos: la presencia de conocimiento relacionado, que posibilita la comunicación; el carácter instrumental de las expresiones, que sirven para influenciar el pensamiento y el comportamiento del auditorio; y el carácter verbal de las expresiones como actos de habla indirectos, que proporcionan información implícita y explícita. En el caso de las manipulaciones verbales en contextos públicos, la intencionalidad muestra dos vertientes: la intención explícita de persuadir a un auditorio de la aceptabilidad o no de determinada opinión, y la intención implícita de ganar al auditorio para una determinada causa. Por tanto, como actos de habla, las manipulaciones se procuran de forma implícita, pero con apoyo explícito; recurriendo al contexto social y espiritual que ha facilitado la interacción entre el orador y el auditorio, y que determinará el resultado de la interacción; no recurriendo a la disposición del auditorio a comprometerse racionalmente; recurriendo a su disposición a recibir y seguir instrucciones; y moldeando la mentalidad y las actitudes del auditorio, preparándole para hablar, pensar, sentir y actuar de un modo concreto. Como resultado, la manipulación será eficaz.

Por otro lado, la comunicación se rige por una especie de contrato implícitamente estipulado entre hablantes bajo el supuesto de que nuestros discursos son sensatos, están justificados y responden a la verdad. Tal contrato desarrolla un papel fundamental en el complejo proceso interpretativo de la comunicación. Grice (1991, p. 516) lo llamó principio de cooperación: «Haga usted su contribución a la conversación tal y como lo exige, en el estadio en que tenga lugar, el propósito o la dirección del intercambio que usted sostenga». Es un principio de racionalidad comunicativa que desempeña un papel ético y epistemológico. A juicio de Grice es aplicable a cualquier interacción, incluida la no verbal. Por supuesto, también en la manipulación, aunque los manipuladores no siempre digan la verdad y se sirvan de la cooperación para enmascarar sus propósitos. Grice acuñó el término implicatura para referirse al acto de dar a entender o implicar alguna cosa diciendo algo más (p. 513): las implicaciones pragmáticas y contextuales en cuanto distintas de las implicaciones lógicas. A diferencia de una implicación lógica, una implicatura conversacional depende del contexto y es inferida por el interlocutor partiendo del presupuesto de que quien habla busca la cooperación para alcanzar la mayor eficacia comunicativa.

Junto al principio de cooperación hay que postular un principio de cortesía que posee un papel regulador superior y que es útil para preservar el equilibrio social y las relaciones que nos llevan a suponer que nuestros interlocutores están siendo cooperativos. Hay cuatro máximas conversacionales, cuyas generalizaciones gobiernan la conducta racional cooperativa. La máxima de 
cantidad: hay que dar la información necesaria y suficiente, teniendo presentes los objetivos de la conversación. La máxima de cualidad: hay que hacer que en nuestra conversación reine la verdad (no diciendo lo que se cree falso o carece de pruebas). La máxima de relación o relevancia: hay que ir al grano y decir lo que es relevante. Y la máxima de modo: hay que ser claro, escueto y ordenado. Estas máximas son filosóficas y retóricas. De ellas surgen muchas figuras retóricas, sobre todo las figuras de lo que no se dice, de lo que se suprime o se sugiere, como la elipsis, la preterición, la reticencia, la alusión o el énfasis. En términos de argumentación retórica, dan origen al entimema, entendido como un argumento cuyos elementos no se explicitan íntegramente.

Conviene señalar que las cuatro máximas se fijan no tanto para ser rigurosamente respetadas, como para ser infringidas, con el fin de comunicar algo de forma indirecta. No son los mandamientos a observar siempre, sino los medios para decir de forma diferente lo que se quiere decir o para decir lo que no se puede decir porque es censurable o impertinente, o para transmitir significados supuestos de forma socialmente aceptable. Si el incumplimiento de la máxima se ha hecho con espíritu cooperativo, se origina una implicatura conversacional, y si no es cooperativo, se llega a una falacia (cf. Martinich 1984). ${ }^{6}$ Para los ejemplos del Julio César, el incumplimiento de la máxima de modo será recurrente, pues en ellos habrá poca claridad, brevedad y orden, y la ambigüedad reinará por doquier. A río revuelto, ganancia de manipuladores.

\section{Situación de PARTIDA Y MOdo DE PROCEDER DE ANTONIO: \\ EL PAPEL DE LA IRONÍA}

Resulta natural comparar el estilo de Bruto, una declaración de públicas razones (3.2.7), con el estilo apasionado de Antonio, y leerlo como una apelación a la razón que queda sin fuerza ante la apelación más eficaz de éste a las emociones. De hecho, Bruto se presenta como hombre de honor y de razón, que se dirige a la razón de su auditorio («Oíd mis razones (...) y avivad el sentido para poder juzgar» $(3.2 .14,17-18)$ ), pero de forma distanciada. Aunque ello puede hacernos pensar que Bruto está tratando de justificar lógicamente las verdaderas razones y su acción, nada de ello encontramos en su discurso. La acusación de ambición contra César se desliza entre las declaraciones de su afecto y amor por él y queda sin justificar, de modo que acabará diciendo que «Las razones de su muerte constan en el Capitolio» (3.2.35-36). Además, introduce la retórica de forma muy ingeniosa para persuadir a un auditorio que exige «una explicación» (3.2.1) y le ofrece una antimetabole sustanciada

6 Esto puede explicar por qué, en un intercambio argumentativo, una falacia puede entenderse como un movimiento manipulador referido al contexto pragmático (cf. Van Eemeren y Grootendorst 1992, p. 103). 
en la tautología «Creedme por mi honor y tened presente mi honor para poder creer» (3.2.15-16), como resultado de invertir los términos «creer»y «honor» y en contra de la máxima de cantidad. También introduce un falso dilema entre la muerte de César y el amor a Roma; una oscura antífrasis ${ }^{7}$ que juega con la muerte/vida de César y la libertad/esclavitud de su auditorio; y la combinación de una anáfora y una epífora centrada en las posibles ofensas a la plebe por su acto. ${ }^{8}$ Por tanto, Bruto también es un manipulador, pero un manipulador que fue manipulado previamente y de forma sutil por Casio. Mankiewicz nos muestra esta sutileza en su sencillo monólogo en una escena de gran belleza visual, cuando Casio planea echar por la ventana de Bruto varias cartas como si fuesen de diferentes personas, apelando a su gran concepto de Bruto y «aludiendo sordamente a la ambición de César» (1.2.319-320), para ganarse la complicidad del amigo, pues «qquién es tan puro que no se deje seducir?» (1.2.312): Casio va caminando, mirando a la cámara, y ésta pasa por encima de él, para reflejar cómo el espacio público por el que ha caminado está siendo barrido por el viento, preámbulo de la inmediata conjura.

Ahora bien, ¿es Casio un sutil manipulador o un sutil seductor? Sus palabras citadas reflejan lo segundo. En una escena anterior, Bruto se ha percatado de ello y le dice: «Del aprecio que me tienes no recelo; a dónde quieres llevarme lo imagino» (1.2.168-169). Podríamos decir que Casio actúa como catalizador para que Bruto tome conciencia de la situación y «hable, actúe y remedie», como podrá leer en una de aquellas cartas (2.1.47). De hecho, en otra escena, Casio le dice que quisiera que «no fuese tan ciego» y que «como sabes que sólo puedes verte reflejado, yo seré el espejo que te muestre verazmente lo que ignoras» (1.2.72-74). Así que Casio sabe de la falta de conocimiento que Bruto tiene de la situación y de sí mismo y, por ello, podríamos pensar que está actuando de partera, en el sentido socrático. Pero, al declarar en su monólogo que conviene que «a tu noble metal podemos darle un nuevo temple» (1.2.309), Casio nada entre la seducción y la sutil manipulación. La fuerza de sus palabras se sirve de la debilidad de carácter de Bruto y su argumento clave transcurre, contra la máxima de modo, en términos alusivos, oblicuos,

7 Es una figura retórica que consiste en dar a un objeto o persona un nombre que apunta a cualidades contrarias a las que realmente posee. También se dice de una expresión que significa irónicamente lo contrario de lo que se quiere decir.

8 La anáfora es una figura retórica que consiste en la repetición de una o más palabras al comienzo de la frase, y la epifora en la repetición de una o varias al final de frases sucesivas. Bruto las usa magistralmente entrelazadas de preguntas retóricas -que, sin esperar respuesta de la plebe, las da por asentidas- en el fragmento: «¿Quién hay aquí tan servil que quiera ser esclavo? Si hay alguien, que lo diga, pues le habré ofendido. ¿Quién tan bárbaro que no quiera ser romano? Si hay alguien, que lo diga, pues le habré ofendido. ¿Quién tan ruin que no ame a su patria? Si hay alguien, que lo diga, pues le habré ofendido» (3.2.28-32). 
que transmiten «reflexiones ambiciosas, pensamientos importantes» (1.2.55), de los que Bruto acaba por hacerse eco al calificarlos de «cuestiones de tanto peso» (1.2.176) y que apuntan a su vanidad e imagen y al ideal de la tradición romana. Sin embargo, en su soliloquio justificativo de la necesidad de la muerte de César, reconoce no tener «otro motivo para eliminarle que no sea el bien común» (2.1.11-12), centrándose en una serie de metáforas sobre la naturaleza humana y acabando en el temor de lo que César podría hacer. Así que, como a la serpiente, «hay que matarle en el cascarón» (2.1.34), a sabiendas de que mata al «primer hombre del mundo» (4.3.23), por ser ambicioso. Sin saberlo, Casio y Bruto han sentado las bases del discurso de Antonio, de las cuales heredará la ambigüedad que, al añadirle la ironía, convertirá en una tela de araña que atrapará a los conjurados.

La situación con que Antonio se encuentra no es favorable: tiene permiso de los conjurados para dirigirse a la multitud; está sobre «un terreno resbaladizo» (3.1.205); tiene el control de la información, al presumir que sabe lo que Bruto ha dicho; y el auditorio conoce los motivos de su intervención, aunque no sus verdaderos objetivos. En su discurso, podemos identificar cuatro partes y un epílogo: interpretación de la ambición de César y reflexión sobre su amistad; alusión al testamento y poder de César; elogio de éste y recreación del asesinato; declaración de desconocimiento de la oratoria y desacuerdo con el motín; y lectura del testamento, como epílogo. Pero, ¿cómo procede en estas diferentes fases del discurso? (1) Partiendo de los argumentos de Bruto sobre la supuesta ambición de César, ya compartidos por su auditorio, pero reinterpretando la ambición, con lo que las consecuencias serán diferentes. (2) Actuando de modo aparentemente natural y mostrándose respetuoso con su auditorio (cortesía positiva) -y con los conspiradores (cortesía negativa)-, para quien va desgranando sus argumentos pausadamente, con rodeos, enmascarando sus intereses y para que pueda interpretarlos con el significado que le conviene y sacar las consecuencias que también a él le interesan. (3) Ocultando su plan (al contrario de Bruto que explica el suyo) para controlar el proceso. (4) Explotando materialmente, pero de forma ascendente, la escasa lealtad que la multitud aún profesa a César, tras oír los argumentos de Bruto. (5) Explotando formalmente las máximas conversacionales de manera ambigua e irónica para presentar sus argumentos. (6) Explotando las indirectas y sugiriendo de forma velada y oscura. (7) Subrayando y repitiendo todo cuanto beneficia al auditorio y coincide con sus propias intenciones. (8) Aparentando saber más de lo que sabe y encontrarse agobiado por un conflicto interior que puede estar relacionado con lo que realmente sabe sobre la muerte de César, por el pesar que le ha causado y por las consecuencias negativas que puede tener para la multitud. (9) Rentabilizando su cortesía y la atención que la multitud le dispensa, hasta el punto de hacerse imprescindible para que ésta pueda conocer el testamento 
de César. (10) Adoptando lentamente una posición física igualitaria y, a veces, subordinada, pero intelectualmente superior, respecto de la multitud. (11) Haciendo recaer sobre ésta las consecuencias políticas del suceso, pero incluyéndose él mismo cuando le interesa. (12) Dirigiendo estratégicamente preguntas retóricas a la multitud, centradas sobre (la supuesta ambición de) César, sobre el llanto de la multitud (o para provocarlo) o sobre su supuesta subordinación a la plebe. Y (13) apelando continuamente a las emociones, a las suyas, a las de César y a las de la multitud.

Una mención especial merece la ironía, una de las figuras retóricas más eficaces en la persuasión. Aparece al usar una palabra con un significado opuesto a su significado literal. Aunque suele usarse para acentuar un error o una mala acción, en la conversación incumpliría el principio griceano de cooperación. Lo que permite entender que uno ha dicho $x$, pero quiere decir lo opuesto, no- $x$, es la naturaleza racional y cooperativa de la conversación. Por ello, Antonio la toma como un medio para reforzar sus relaciones con y ganarse al auditorio. Todo ello se percibe en el film en el modo en que habla, en su tono y ademanes. Desde un punto de vista crítico, la ironía le permite distanciarse de las tesis de los conspiradores y adoptar una nueva perspectiva con fines inconfesables, pues debe auto-protegerse para reforzar sus tesis, a costa de hacer más complejo su lenguaje y la estructura de su discurso, lo que le lleva a la ambigüedad y a la imprecisión. La asociación de ironía y ambigüedad se plasma en la explicación intencionadamente confusa de los datos que sirven de base a sus declaraciones. Como ya hemos apuntado, la ambigüedad es precisamente la marca que define globalmente el Julio César, porque en él todo es interpretable y nada se presenta de forma definitiva: ni personajes, ni palabras, ni acciones.

Cuando relacionamos el modo de proceder con las máximas conversacionales, nos llevamos alguna sorpresa. Así, de acuerdo con la máxima de cantidad, por un lado, Antonio da más información de la necesaria, a veces exagerando, pues, si su propósito es incitar al motín, el epílogo es un añadido innecesario. Pero, por otro, podemos pensar que da menos información de la necesaria, pues la lealtad a «los hombres de honor» está forzándole a callar algo que puede ser deshonroso para ellos y que el auditorio podría no aceptar. Por tanto, en este caso, lo que queda silenciado podría ser una verdad relevante, atentando contra la máxima de relación. También podría estar actuando con deliberada oscuridad, atentando contra la máxima de modo, y permitiendo otras interpretaciones alternativas. Tal vez sea esta la razón de la longitud del discurso: dar tiempo al auditorio para que vaya sacando las conclusiones pertinentes de las otras posibles interpretaciones, a la vez que se le va reconduciendo al objetivo perseguido, atentando de nuevo contra la máxima de cantidad. Incumple, además, la máxima de relación recurriendo, con frecuencia, 
a claves que facilitan la asociación de ideas, los presupuestos, las pistas, etc. que contribuyen a cambiar la posición del auditorio.

De acuerdo con la máxima de cualidad, Antonio parece buscar la verdad que hay detrás de la muerte de César, argumentando a partir de las declaraciones de Bruto sobre su supuesta ambición, y así parece querer manifestarlo, pero de una forma tan oscilante que deja al auditorio preguntándose sobre la posibilidad de que haya algo que él sabe -como hemos sugerido-, pero que no puede decir con total claridad, tal vez por la consabida lealtad, lo cual muestra, por otro lado, que desea ser sincero, pero que hay algo que se lo impide. Además, su permanente ironía y deliberadas contradicciones atentan también contra la máxima de cualidad. De hecho, sus declaraciones iniciales contradicen su práctica posterior. Comienza diciendo: «Vengo a enterrar a César, no a elogiarlo» (3.2.78), pero todo su discurso se dedica a destacar el valor moral, político y humano de César, hasta convertirlo en un mártir. Contra la máxima de modo, Antonio es reiterativo, desordenado y ambiguo al tratar los problemas. Se mueve en un círculo informativo, en cuyo seno, a través de preguntas -retóricas y, así, en contra de la máxima de cualidad-, respondidas de forma muy general, teje una red de significaciones y emociones con la colaboración de la multitud en la que ésta quedará atrapada, camino del motín, por efecto de la manipulación. Se cumple así aquello que Austin dijera al defender la necesidad de analizar el acto de habla global en la situación de habla global, situación que puede incluir las convenciones que explican actos como argumentar y los efectos producidos «sobre los sentimientos, pensamientos o acciones del auditorio, o de quien emite la expresión, o de otras personas», con algún «propósito, intención o designio» (1990, pp. 95 y 145).

\section{Momentos ESTelares DE UN DISCURSO MANIPULADOR}

La presencia de Antonio, el más romano entre los romanos en el film, subraya su brillante sentido político. Dialoga, pero en realidad juega, con la plebe, variando el ritmo y con pausas plenas de disimulo para evaluar el efecto que produce su estrategia retórica. En concreto, dos primerísimos planos de su rostro nos dejan ver cómo está prestando oídos a la evaluación que la plebe hace de sus palabras, al tiempo que muestra su satisfacción por los efectos. Se detiene sigilosamente cada vez que pronuncia las palabras «ambición» u «hombres de honor», para que la plebe vaya asociando ideas. La mostración del cadáver va precedida de un primer plano del ciego adivino, que deja ver simultáneamente la acción de Antonio, y va seguida de un barrido por parte de la cámara de los rostros de los primeros espectadores del auditorio para mostrar su aflicción e ira in crescendo y, como contraste, su ceguera ante las verdaderas intenciones de Antonio. 
Desde el comienzo mismo de su discurso, Antonio finge aceptar la tesis de Bruto de que César «fue ambicioso», como «os ha dicho» (3.2.82), para pasar después a socavarla, cambiando el significado de algunas palabras clave, a pesar de que apuntará: «No pretendo rebatir lo que ha dicho Bruto» (3.2.104). Asimismo indica que habla «con la venia de Bruto y los demás» (3.2.85), con lo que pretende tintar de verdad sus declaraciones, lo que a la postre resultará engañoso. En el contexto emocional y sutilmente cambiante en que se mueve -y del que en buena medida él será el motor, aunque acabe negándolo («Si yo fuese a excitar vuestras pasiones a la saña y al motín» (3.2.126-127))-, repite la tesis «Pero Bruto dice que César fue ambicioso, y Bruto es un hombre de honor» (3.2.90-91, 97-98) a intervalos regulares y estratégicos, lo que provoca, mediante una persuasiva antífrasis, que las palabras «honor» y «ambición» asuman significados opuestos e irónicos, y la tesis de Bruto acabe por volverse contra él en lo referente a la ambición. De hecho, volverá a repetir la tesis inmediatamente (3.2.102-103), sugiriendo que en realidad significa algo diferente, a saber, que «César no fue ambicioso, y Bruto no es un hombre de honor», de modo que la multitud puede sacar por sí misma una conclusión que Antonio no ha expresado: «¡Hombres de honor! ¡Traidores es lo que son!» (3.2.158). También al comienzo del discurso, Antonio declara que viene «a enterrar a César, no a elogiarlo» (3.2.78), para precisar después que «viene a hablar en las exequias de César» (3.2.88) «con la venia de Bruto y los demás» (3.2.85), como hemos indicado, pero con la exigencia de Bruto de que «No nos acuses en tu oración fúnebre. Habla de César todo lo bien que sepas y di que lo haces con nuestro permiso» (3.1.263-265). Observemos, además, que lo que podría declarar sería un conjunto de verdades incómodas, ya que se debatiría entre decir lo que le han autorizado a decir -supuestamente una mentira, que es lo que dice Bruto-y, al mismo tiempo, arrojar dudas sobre ello, pues «estoy aquí para decir lo que sé» (3.2.105) -supuestamente una verdad, que le permite explotar la cortesía positiva-, que no es otra cosa que -dirigiéndose a la multitud-«lo que sabéis» (3.2.228). Demasiada ambigüedad, contra la máxima de modo. Demasiadas indirectas, demasiadas implicaturas para que la multitud pueda captar de inmediato toda la ironía de su mensaje, con efectos retóricos deliberados.

Al inicio también de la primera parte, hay una afirmación de Antonio que, además de parecer un comentario muy marginal a su declaración de que no va a elogiar a César, tiene el aspecto de guardar poca relación con lo que sigue: «El mal que hacen los hombres vive tras su muerte; el bien solemos sepultarlo con sus restos» (3.2.79-80). Podemos preguntarnos acerca del significado de los vocablos «mal»y «bien» en este contexto, pues parecen no estar exentos de ambigüedad. ¿Se refiere con «bien» a las buenas acciones que hizo César en vida y que con su muerte no tienen ningún reconocimiento? Si es así, entonces Antonio está criticando de forma velada e irónica a sus asesinos. ¿Se refiere 
con «mal» a sus malas acciones o a los asesinos? Si es a lo primero, ¿qué queda realmente de sus malas acciones? Si se refiere a la ambición en el sentido de Bruto y los demás, con su acción el problema ha quedado zanjado. Si se refiere a la ambición en el sentido de Antonio, está incurriendo en una contradicción y, por lo tanto, no parece que sea practicable esta hipótesis. Por ello, parece viable que con «mal» se esté refiriendo a los asesinos. ¿Por qué? Porque en cierto modo los asesinos son deudores de César en lo político, pero también en lo personal, hasta el punto de que Bruto lo señala como «mi mejor amigo» (3.2.42), a quien ama, además de ser su hijo adoptivo. Ahora bien, esta hipótesis también sería de aplicación a Antonio, pues éste dice de César que era «mi amigo, un amigo fiel y leal» (3.2.89), a quien quería (3.2.222). Sin embargo, Antonio no le ha matado, es decir, no es un amigo que haya apuñalado al objeto de su amistad. Así que la hipótesis de que Antonio se esté refiriendo a los asesinos cobra fuerza a medida que avanza su discurso y lo hace con gran contundencia física al referir que «aquí le apuñaló su muy amado Bruto» (3.2.181) y con gran contundencia racional y moral al referirse antes a aquellos «hombres de juicio», a aquellos «hombres de honor que han acuchillado a César» (3.2.156-157), mezclando y aproximando hábilmente dos términos tan contradictorios como «apuñalar» $\mathrm{y}$ «amar», y «honor» y «acuchillar», en contra de las máximas de cualidad y de relevancia. La cruel ironía que destila este choque conceptual, así como el temor de Antonio a haber ofendido a «los espíritus más dignos y preclaros del momento» (3.1.176), no escapa ya a la multitud que ha empezado a inclinar la balanza hacia el platillo de tan sutil manipulador, que hasta ese momento había ido madurando las reiteradas referencias a tales «hombres de honor» con una no disimulada cortesía negativa.

Al final de la primera parte del discurso, Antonio se detiene con el pretexto de recobrar la compostura, pero es para calcular -fingiendo- sus efectos sobre la multitud, y llamar directamente la atención sobre él y no sobre el cadáver, buscando la cooperación del auditorio. En la segunda parte, recurre a elementos externos al discurso que le permiten complementarlo y avanzar en sus propósitos: el testamento, la túnica ensangrentada y el cuerpo de César. Mientras declama este fragmento (3.2.172-199), tras el «Baja» (3.2.166) que le ordena la plebe, permite que ésta rodee el cadáver y, sosteniendo la túnica, recrea el asesinato. Al comienzo proliferan los imperativos -en correspondencia con el que le ha hecho descender-: «Mirad», «Ved», «Juzgad» (3.2.179-180, 187), construyendo el discurso de forma visual, pero apelando, no sin ironía, a la razón de la multitud y a la suya propia en detrimento de la de los conspiradores, ${ }^{9}$ hasta el final en que revela el propio cuerpo: «iMirad, aquí está él!» (3.2.201).

9 No parece que la versión española textual y fílmica («iAh cordura! Te has refugiado en las bestias y los hombres han perdido la razón» (3.2.108-109)) consiga captar, en toda su ironía, 
Como argumento visual, el cadáver demuestra «la vil traición» de los conjurados (3.2.197) ${ }^{10} \mathrm{y}$, de forma destacada, la grandeza de Antonio. En esta fase, su discurso adscribe vida a los objetos inanimados. Utilizando de forma manipulada una prosopopeya,${ }^{11}$ que recapitula lo que ha dicho -sin que se perturbe su ánimo-, y a través de un proceso de transferencia, configura el espacio de la voz de César (es decir, Antonio), interpelando a la multitud para conmoverla. Así, las heridas son «pobres, pobres bocas mudas» que hablan «por mí» (3.2.229-230), transformando el cuerpo en acto de habla que le permite hacer cosas en su provecho. La «sangre de César» corrió «hacia la puerta para ver si era Bruto quien llamaba tan cruelmente» (3.2.183-185), mientras que la estatua de Pompeyo «estaba chorreando sangre» (3.2.194), en un atentado contra la máxima de cantidad. Al descubrir el cuerpo libera las fuerzas del caos y la destrucción: «¡Venganza! ¡Corred! ¡Buscad! ¡Quemad! ¡Abrasad! ¡Matad! ¡Que no quede vivo un traidor!» (3.2.209). Esta es la clave de la vitalidad de su lenguaje, la energía que le permite mantener el tamaño de su manipulación.

Finalmente, la explicación que Antonio ofrece de sus escasas dotes oratorias (3.2.225-227) es la conclusión apropiada para una actuación que está impregnada de ironía, esencia de su discurso y en contra de la máxima de cualidad, y que va desde su persona de «hombre claro y franco» (3.2.222), hasta las formas más específicas de antífrasis, a la cual ya nos hemos referido, y preterición. ${ }^{12}$ Ambas figuras forman parte de sus técnicas más eficaces y encierran una forma de ironía que funciona desmintiendo aquello que precisamente desea subrayar. Así, repitiendo la palabra «injusto» varias veces en cinco líneas (3.2.128-132), insinúa que se ha hecho una injusticia negando al mismo tiempo que se haya actuado de forma injusta. Pretendiendo calmar a la multitud, evitando excitar sus «pasiones a la saña y al motín» (3.2.127), logra sus propósitos, aunque lo esté negando. Su forma de proceder con el testamento, «que, perdonadme, no pienso leer» (3.2.136), también recurre a la preterición: al enumerar todas las razones para mantener guardado el testamento, describe exactamente la forma

las palabras de Antonio y sus significados en la versión original: «O, judgment, thou art fled to brutish beasts, / And men have lost their reason». El adjetivo brutish (bruto) es rico en implicaciones y apunta claramente a Bruto, quien como hombre ha perdido la razón, se ha convertido en una animal irracional, en una bestia brutal, y si Antonio ha venido a decir lo que sabe, con la venia de los conspiradores, lo primero que dice es justamente eso.

10 Según Quintiliano (1999, VI, I, 31), la toga ensangrentada de César precediendo su cortejo fúnebre enfureció al pueblo romano. Sobre argumentos visuales, véase Alcolea 2011b.

11 Figura retórica de pensamiento que consiste en atribuir a las cosas inanimadas o abstractas, acciones y cualidades propias de seres animados, etc., confiriéndoles una máscara o rostro (prosopon).

12 Figura retórica oblicua consistente en declarar que se omite algo, cuando de hecho se aprovecha la ocasión para llamar la atención sobre ello, a veces de forma enfática. 
en que «arderíais de rabia, os volverías locos» (3.2.149). El discurso de Antonio empieza en su segunda parte y termina en la tercera con claras referencias «al motín», que la multitud acaba haciendo suyo (3.2.127, 234-235). Sin ninguna preocupación por la moral o la verdad, sus energías se centran hasta el final en la manipulación. Por ello mantiene sus pies de forma eficaz en «un terreno tan resbaladizo» (3.1.205). La imagen del fuego asociada a su discurso («tiene los ojos rojos como el fuego» [3.2.120]), su fingida renuencia a hacer que la multitud arda de rabia (3.2.149), sugieren que sus palabras echan chispas de verdad: «Quemad su cadáver en lugar sagrado y con las llamas incendiad las casas de los traidores» (3.2.259-260), acaban diciendo los ciudadanos. Pero no olvidemos que, aunque la manipulación de Casio es más sutil, también sus «débiles palabras» arrancan a Bruto «chispas de entusiasmo» (1.2.183-184).

\section{CONCLUSIÓN: HACER FRENTE A LA MANIPULACIÓN CON LA ARGUMENTACIÓN RETÓRICA}

Aunque la situación que encontramos en el Julio César está ligada a la política, el discurso público manipulador puede aparecer en cualquier ámbito. La manipulación es un medio al servicio de unos fines más o menos nobles o legítimos. ¿Es noble la causa de Bruto? ¿Es legítima la aspiración de Casio a la hora de «seducir» a Bruto? ¿Es legítima la actuación de Antonio? A veces también es un medio al servicio de los fines más mezquinos. Que Antonio queda retratado por estos fines él mismo nos lo muestra en el film con una leve y malévola sonrisa de satisfacción, y en el texto shakesperiano al decir a su criado que Octavio y Lépido «habrán [sido] informados de cómo he sublevado al pueblo» (3.2.275-276). Hallar un antídoto contra la manipulación es realmente difícil. Solamente la participación activa ante la recepción de un discurso puede ponernos en guardia de forma crítica, racional y razonable, y ayudarnos a no caer en las redes del manipulador.

Si, como recordaba Kant en su Crítica de la razón pura, «el criterio para saber si el tener por verdadero es convicción o mera persuasión es (...) externo, y consiste en la posibilidad de comunicarlo y en comprobar su validez para toda razón humana», de modo que haya concordancia entre todos los sujetos (A820, B848), entonces, para llegar a esta concordancia, se ha de producir una discusión en la que salgan a la luz las razones por las que es preciso mejorar todo un espectro que puede ir, por ejemplo, desde las bases de la información -el caso de la plebe manipulada en el Julio César-, hasta las reglas y el modo de proceder en la discusión - parcialmente fijadas por Bruto y Antonio en los momentos que preceden a su comparecencia ante la plebe. Así, la manipulación acaba produciéndose porque en buena medida no se permite que «el proceso de argumentación» sea «un proceso autocorrectivo», en el que todos los agentes pueden participar activamente, por decirlo con Habermas (2002, p. 58). 
Con todo, nuestros análisis podrían llevarnos a concluir que debemos ponernos en guardia contra la retórica como arte proveedora de argumentos engañosos. Sin embargo, el estudio de la retórica o, cuando menos, de los aspectos retóricos de la argumentación puede ayudarnos a descubrir si una persona tiene la intención de manipularnos y, por ello, estar al servicio de fines perfectamente respetables. ¿No es esta la circunstancia en que se encuentra Sócrates con los sofistas en el Eutidemo (285a-b)?: con su fina ironía Sócrates hace frente a la peor retórica con una retórica válida y acertada. Por ello, los antiguos no se equivocaron al reunir en este arte tanto los elementos racionales como los emotivos del proceso de argumentación. Así que en todos los argumentos la retórica es inevitable, de modo que podemos y debemos hablar de argumentación retórica, avanzando hacia un modelo (cf. Alcolea 2011a) en el que se deje sentir el peso de los mejores argumentos.

\section{BIBLIOGRAFÍA}

ALCOLEA, J. 2011a: «Cap a un model d'argumentació retòrica», en E. Casaban (ed.), XVIII Congrés Valencià de Filosofia. València, 25-27 de març de 2010. Valencia: SFPV, pp. 157-171.

—, 2011b: «Argumentos visuales», en L. Vega \& G. Bolado (eds.), La argumentación en el discurso público. Santander: Parlamento de Cantabria, pp. 121-146.

ARISTÓTELES 1990: Retórica, trad. Q. Racionero. Madrid: Gredos.

AUSTIN, J.L. 1990: Cómo hacer cosas con palabras, trad. G. R. Carrió y E. A. Rabossi. Barcelona: Paidós.

GILBERT, M.A. 1997: Coalescent argumentation. Mahwah, NJ: L. Erlbaum.

GRICE, H.P. 1991: «Lógica y conversación», trad. J. J. Acero. En L. M. Valdés (ed.), La búsqueda del significado. Madrid: Tecnos, pp. 511-530.

HABERMAS, J. 2002: Acción comunicativa y razón sin transcendencia, trad. P. Fabra. Barcelona: Paidós.

ILATOV, Z.Z. 1993: «Manipulations in argumentation», Argumentation, 7, pp. 359-367. KANT, I. 1989: Crítica de la razón pura, trad. P. Ribas. Madrid: Alfaguara.

MANGAN, M. 1992: «I am no orator: the language of public spaces». En L. Cookson y B. Loughrey (eds.), Julius Caesar. London: Longman, pp. 66-78.

MANKIEWICZ, J.L. 1953: Julio César. Warner Bros.

MARTINICH, A.P. 1984: Communication and reference. Berlin: W. de Gruyter.

NETTEL, A.L. \& ROQUE, G. 2012: «Persuasive argumentation versus manipulation», Argumentation, 26/1, pp. 55-69.

PLATÓN 1983. Diálogos I, trad. J. Calonge y otros. Madrid: Gredos.

QUINTILIANO, M.F. 1999: Sobre la formación del orador: doce libros, trad. A. Ortega. Salamanca: Universidad Pontificia, tomo II.

SHAKESPEARE, W. 2001: Julio César, trad. Á.-L. Pujante. Madrid: Espasa-Calpe. —, 2002: Julius Caesar. Hauppauge, NY: Barron's.

SPERBER, D. \& WILSON, D. 1994: La relevancia, trad. E. Leonetti. Madrid: Visor 
Dis.

VAN DIJK, T. A. 2009: Discurso y poder, trad. A. Bixio. Barcelona: Gedisa.

VAN EEMEREN, F.H. \& GROOTENDORST, R. 1992: Argumentation, communication and fallacies. Hillsdale, NJ: Erlbaum.

VEGA, L. \& OLMOS, P. (eds.) 2011: Compendio de lógica, argumentación y retórica. Madrid: Trotta.

WYKE, M. 2004: «Films style and fascism: Julius Caesar», Film studies, 4, pp. 58-74.

Jesús Alcolea Banegas es Profesor Titular de Universidad del Área de conocimiento y Departamento de Lógica y Filosofía de la Ciencia de la Facultad de Filosofía y Ciencias de la Educación en la Universitat de València.

Líneas de investigación

Filosofía de la Matemática, Teoría de la Argumentación

Publicaciones recientes

2011. «Kitcher's naturalistic epistemology and methodology of mathematics». En W. J. González (ed.), Scientific realism and democratic society. The philosophy of Philip Kitcher. Amsterdam / New York, NY: Rodopi, pp. 295-326.

2011. Compendio de lógica, argumentación y retórica, ed. L. Vega y P. Olmos. Coordinador del Área de Retórica J. Alcolea. Madrid: Trotta, 2a ed. corregida y aumentada, 2012.

2013. «Argumentation in mathematics». In A. Aberdein \& I. Dove (eds.), The argument of mathematics. Berlin: Springer, pp. 35-48.

Dirección electrónica: jesus.alcolea@uv.es 